\title{
Optimization Model of Closed Loop Supply Chain Based on System Dynamics and Graph Theory
}

\author{
Ying $\mathrm{Xu}^{1,2}$, Xuemei Zhang ${ }^{1}$ and Yu Hong ${ }^{3}$ \\ ${ }^{1}$ School of Electronic Commerce, Ningbo DaHongYing University, \\ Ningbo City, 315175, China \\ ${ }^{2}$ Business School, Sias International University, \\ Xinzheng City, 451150, China \\ ${ }^{3}$ College of Humanities and Sciences, Northeast Normal University, \\ Changchun City, 130117, China \\ 315345395@qq.com
}

\begin{abstract}
In order to assist in the reverse recovery decision of emergency logistics in sudden natural disasters, this paper conducts the system modeling on the reverse recovery of reusable materials in several disaster areas from the perspective of system dynamics under the principle of rescue satisfaction preference. Through the comprehensive analysis of material demand of disaster areas, the occupancy of resources in reverse recovery and other factors, it establishes the function relation between the recovery frequency and rescue satisfaction, and simulates the system model with the system dynamics software Vensim. Finally, the effectiveness and practicability of the model is proved by an example, based on which the impact of transportation resource change on rescue satisfaction is analyzed. Based on the above research conclusion, this paper provides the decision support and countermeasure for the emergency reverse logistics in China.
\end{abstract}

Keywords: Emergency reverse logistics; System dynamics; System model; Decisionmaking research

\section{Introduction}

With the frequent occurrence of various global large-scale natural disasters in recent years, more and more countries have recognized the importance and urgency of disaster emergency management. As the premise and basis of disaster emergency, how to timely deliver large amount of disaster relief equipment and materials to disaster areas at the fastest speed to meet the demand for all kinds of marterials in rescue is the core of the rescue work. Therefore, emergency material support in natural disasters becomes the research hotspot for various countries and scholars and has made a lot of research results.

Based on the basic principle of system dynamics, this paper conducts a comprehensive analysis on rescue satisfaction from the transportation resource occupied by reusable materials at certain recovery rate, inventory resource and resource shortage caused by delayed recovery, and builts the system dynamics model on recovery frequency of reusable materials and rescue satisfaction. And based on this model the simulation analysis is conducted to forecast and evaluate the relationship between the frequency of materials recovery and rescue satisfaction in different cases of emergency rescue, and assist in management decisions. 


\section{Building of System Dynamics Model}

\subsection{The SD Model Based on Rescue Satisfaction}

According to the above discussion and assumption, the relationship between reverse logistics and rescue satisfaction in natural disasters can be macrocosmically explained with system dynamics. Establish the causal relationship diagram according to dynamic principle of the disaster relief system to describe the relationship between the supply and demand activities of the reverse logistics system and the rescue satisfaction, as shown in Figure 1. In the diagram, the "+" refers that the variable which the arrowhead pointing to increases with the increasing of source variable at the tail; the "-" means that the variable which the arrowhead pointing to decreases with the increasing of source variable at the tail.

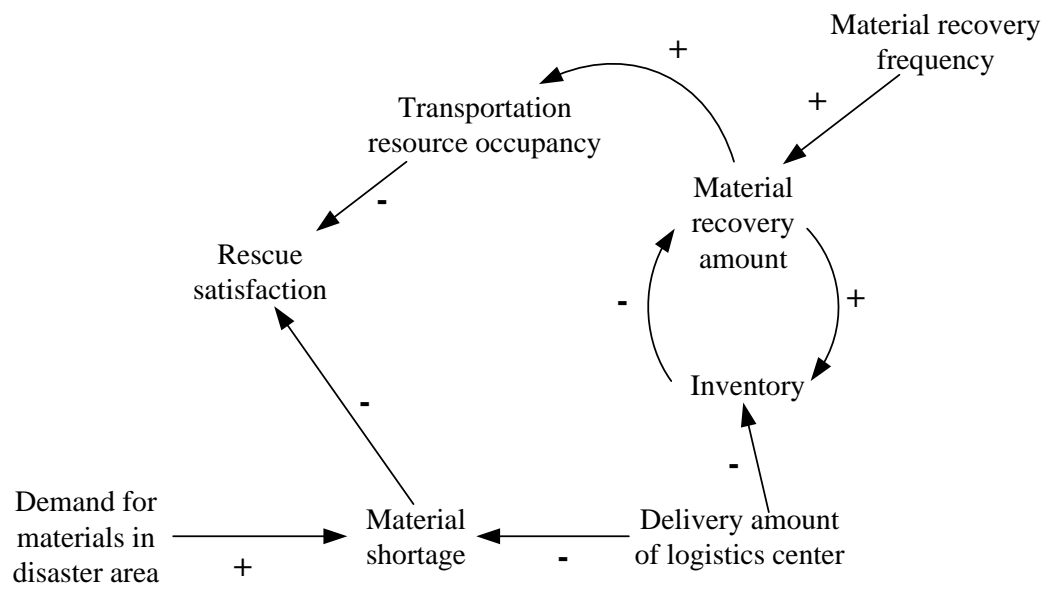

Figure 1. Causal Relationship Diagram for the Reverse Logistics System

1) As the growing demand for supplies in disaster areas, the delivery amounts of logistics center cannot meet the demand. Within a certain period, the rate of material shortage increases and the rescue satisfaction lowers.

2) In order to meet the demand for materials in disaster areas, improve the materials recovery frequency, thus increase the inventory and delivery amounts of the logistics cente and alleviate material shortages.

3) With the increase of materials recovery frequency, the occupancy of rescue transportation resources increases, which will inevitably reduce or delay the transportation of other relief materials, and thus reduce the rescue satisfaction.

\subsection{The Diagram based on the SD Model}

In order to make quantitative analysis on the relationship among the variables in the reverse logistics system, the SD diagram is built based on the causal relation, as shown in Figure 2.

In the model, the box refers the state variables which can be accumulated, such as the inventory of recycled materials and demand backlog, etc. The dual connecting lines on both sides of the state variables refer to the increase or decrease behavior of state variables, which respectively have the inflow and outflow rate measurement, such as recovery and delivery amounts, etc. Other variables connected by a single arrow are auxiliary variables and constants, such as maintenance period and delivery period, etc. Specific settings of variables are as shown in Table 1. 


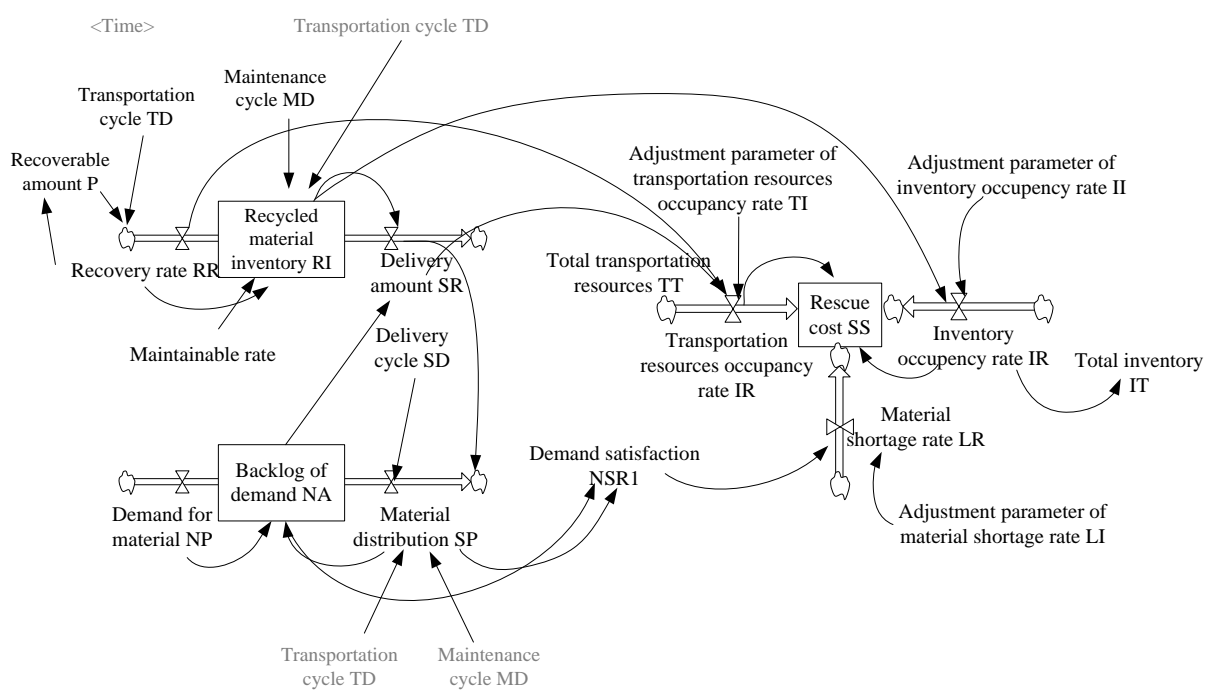

Figure 2. SD Diagram for the Reverse Logistics System

Table 1. Variable Declare Table

\begin{tabular}{|c|c|c|}
\hline Variables & Nature & Declaration \\
\hline $\mathrm{P}$ & $\mathrm{C}$ & Daily recovery amount of certain type of materials \\
\hline $\mathrm{R}$ & $\mathrm{C}$ & Recovery frequency of certain type of materials \\
\hline $\mathrm{RR}$ & $\mathrm{R}$ & Recovery amount of certain type of materials \\
\hline PR & $\mathrm{C}$ & Transport cycle of certain type of materials \\
\hline M & $\mathrm{C}$ & Maintenance rate of certain type of recycling materials \\
\hline RI & $\mathrm{L}$ & Inventory of certain type of materials in logistics center \\
\hline SR & $\mathrm{R}$ & $\begin{array}{l}\text { Delivery amount of certain type of materials within a certain } \\
\text { period }\end{array}$ \\
\hline NP & $\mathrm{R}$ & Demand for certain type of materials in disaster area \\
\hline NA & $\mathrm{L}$ & $\begin{array}{l}\text { Demand accumulation for certain type of materials in } \\
\text { disaster area }\end{array}$ \\
\hline SP & $\mathrm{R}$ & Distribution of certain type of materials in disaster area \\
\hline NSR & $\mathrm{R}$ & $\begin{array}{l}\text { Satisfaction rate of demand for certain type of materials in } \\
\text { disaster area }\end{array}$ \\
\hline IT & $\mathrm{C}$ & Total inventory of logistics center \\
\hline IR & $\mathrm{R}$ & $\begin{array}{l}\text { Proportion of certain type of recycled materials in total } \\
\text { inventory within certain period }\end{array}$ \\
\hline II & $\mathrm{C}$ & Inventory occupancy rate adjustment parameters \\
\hline TT & $\mathrm{C}$ & Total transportation resources within a certain period \\
\hline TR & $\mathrm{R}$ & $\begin{array}{l}\text { Proportion of certain type of recycled materials in total } \\
\text { transported resources within a certain period }\end{array}$ \\
\hline TI & $\mathrm{C}$ & $\begin{array}{l}\text { Transportation resource occupancy rate adjustment } \\
\text { parameters }\end{array}$ \\
\hline LR & $\mathrm{R}$ & Material shortage rate \\
\hline LI & $\mathrm{C}$ & Adjustment parameters of material shortage rate \\
\hline SS & A & Rescue cost \\
\hline
\end{tabular}


As shown in Figure 2, the reverse logistics system is controlled by three submodules: materials recovery submodule, material distribution submodule and rescue cost submodule. Simulate the whole process of material recovery and distribution in natural disaster by setting the corresponding parameters, and calculate the occupied transportation and inventory resources as well as material shortage rate under different recovery amount and frequency. The sum of the three parameters is the total cost SS. The higher the SS is, the lower rescue satisfaction is, and vice versa. The specific discreption is as follows:

1) Rescue cost submodule

The rescue cost submodule describes the total cost of emergency logistics reverse recovery under different states in the actual rescue, which is formed by weighted accumulative addition of material shortage rate, transportation resource occupancy rate and inventory occupancy rate. The logistics cost of emergency recovery is balanced by calculating the proportion of transportation resource and inventory in reverse logistics. The main equations are:

$\mathrm{R} \mathrm{TR} \cdot \mathrm{KL}=(\mathrm{RR} \cdot \mathrm{KL}+\mathrm{SR} \cdot \mathrm{KL}) * \mathrm{DT} / \mathrm{TT} \cdot \mathrm{K} * \mathrm{TI}$

$\mathrm{R}$ IR $\cdot \mathrm{KL}=\mathrm{RI} \cdot \mathrm{K} / \mathrm{IT} \cdot \mathrm{K} * \mathrm{II}$

$\mathrm{R} \mathrm{LR} \cdot \mathrm{KL}=(1-\mathrm{NSR} \cdot \mathrm{KL}) * \mathrm{LI}$

A $\mathrm{PA} \cdot \mathrm{K}=(\mathrm{TR} \cdot \mathrm{KL}+\mathrm{IR} \cdot \mathrm{KL}+\mathrm{LR} \cdot \mathrm{KL}) \times \mathrm{DT}$

TI, II, and LI are respectively transport resources occupancy rate, inventory occupancy rate and material shortage rate adjustment parameters, namely the percentages of each part in total rescue cost. According to the actual situation of disaster relief, adjust the proportion of each part in order to conform to the actual situation. In the actual rescue, if the transportation and inventory resources are sufficient, but the material shortage rate is high, the adjustment parameters of material occupancy rate TI and II should be lowered and the adjustment parameters of material shortage rate LI should be increased.In case of poor transportation due to the occurrence of disasters, the adjustment parameter of transport resources occupancy rate should be appropriately improved in order to meet the actual situation of rescue.

2) Materials recovery submodule

According to the recovery rate of reusable materials in disaster area and the analysis of demand for materials in other disaster areas, set recovery rate to transport the surplus materials to the logistics center, enter the inventory for delivery after cleaning and maintenance. Design various factors according to the actual rescue situation, adjust recovery rate based on rescue satisfaction and balance the resource occupancy and material demand in order to maximaze the rescue satisfaction. The main equations are:

$\mathrm{R}$ RR $\cdot \mathrm{KL}=\mathrm{P} * \mathrm{PULSE}$ TRAIN $(1,0, \mathrm{R}, 30) *$ IF THEN ELSE(Time $>=2, \mathrm{R}, 1)$

$\mathrm{L}$ RI $\cdot \mathrm{K}=\mathrm{RI} \cdot \mathrm{J}+\mathrm{DELAY} 11(\mathrm{RR} \cdot \mathrm{JK} * \mathrm{M}, \mathrm{MD}, 500)-\mathrm{SR} \cdot \mathrm{JK}$

$\mathrm{R}$ SR $\cdot \mathrm{KL}=\mathrm{MIN}(\mathrm{RI} \cdot \mathrm{K}, \mathrm{NA} \cdot \mathrm{K})$

$M$ 为 TD refers the transport time of surplus materials from the disaster area to the logistics center; $\mathrm{R}$ refers the recovery amount per unit time; $\mathrm{M}$ is the maintainable rate; $\mathrm{MD}$ is the time needed for maintenance. According to the actual rescue situation, set the constant value.

3) Materials distribution submodule

According to the demand-driven principle, quickly and quantitatively determine the demand for materials.Alleviate the backlog of demand through material distribution. The main equations are:

$\mathrm{R} N \mathrm{NP} \cdot \mathrm{KL}=\mathrm{RAMP}(100,0,15)$

$\mathrm{L}$ NA $\cdot \mathrm{K}=\mathrm{NA} \cdot \mathrm{J}+\mathrm{NP} \cdot \mathrm{JK}-\mathrm{SP} \cdot \mathrm{JK}$

$\mathrm{R} S \mathrm{SP} \cdot \mathrm{KL}=\mathrm{DELAY} 11(\mathrm{SR} \cdot \mathrm{KL}, \mathrm{SD}, 0)$

A $\mathrm{NSR} \cdot \mathrm{K}=\mathrm{ZIDZ}(\mathrm{SP} \cdot \mathrm{KL}$, NA·K)

$\mathrm{SD}$ refers to the transport cycle from the logistics center to the disaster area. 


\section{Simulation Analysis}

This paper adopts the system dynamics simulation software (Vensim) for analog simulation. The simulation analysis is conducted based on the reverse logistics recovery process after an earthquake. Assuming that the simulation time is one month, and the step size is one day.

Randomly take two data for simulation, and the results are as shown in the figures.

1) As shown in Figure 3, the recoverable amount $P$ of reusable materials $M$ in the plcae $A$ is generated by random function, and the fluctuations of Sim1 and Sim2 show the uncertainty of the whole recovery system.

2) As shown in Figure 4, with the uncertainty of recovery amount, althouth there is subtle difference in the results of the two stochastic simulations due to the difference of sampling values, the curves of Sim1 and Sim2 present the similarity on the whole. This similarity has proved the robustness of the model, which is in line with the requirements of "the relative insensitivity of system dynamics model to parametric variation".

The above analysis shows the availability of computational results of the simulation model.

Recoverable amount $\mathrm{P}$

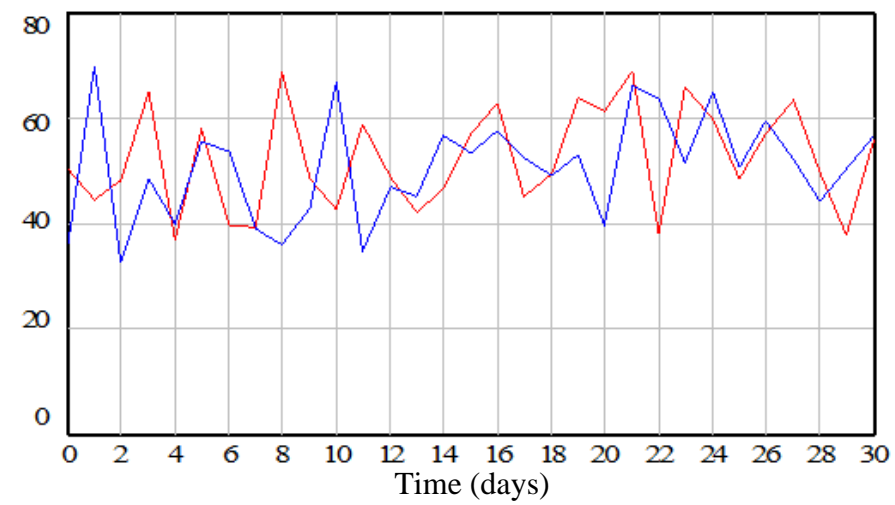

Recoverable amount $\mathrm{P}:$ Sim2

Recoverable amount $\mathrm{P}:$ Sim 1

Figure 3. The Simulation Results Diagram of $P$

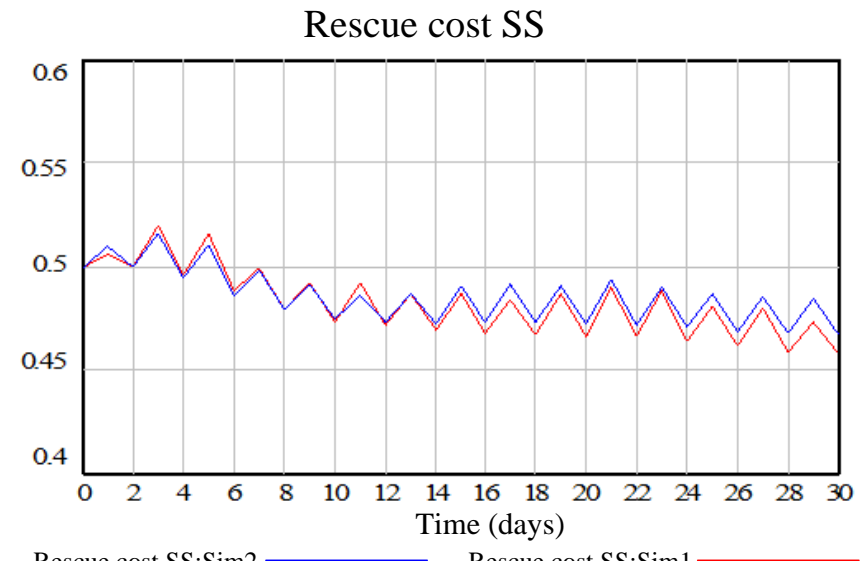

Figure 4. The Simulation Results Diagram of SS 
In actual rescue process, materials, information and logistics resources are all in short supply. But any negligence due to the shortage of resources in rescue can cause serious consequences. In this case, rapid decision-making is especially important. Therefore, managers must make rapid decisions under the condition of the lack of information and resource conflict to save more victims. The system model in this paper will provide assistance and guidance for the decision-making in such danger. The following case will explain the practicability of this model.

The daily recovery amount of reusable material $M$ in the main disaster area $A$ has uncertainty, which varies from 30 to 70 pieces. The preliminary forecast of the demand for material $\mathrm{M}$ in the secondary disaster area $\mathrm{B}$ is 50 pieces per day. It will take 2 days to deliver the materials form the main disaster area A to the logistics center, another 2 days for maintenance in the logistics center, the maintenable rate is $96 \%$ and the delivery time the logistics center to the secondary disaster area B is 1 day. Two assumptions are made as follows:

1) Assuming that the transportation and inventory conditions are good in the actual rescue process, set the adjustment parameter of transportation resources occupancy rate TI and inventory occupancy rate adjustment parameter II respectively as 0.2 and 0.1 , and the material shortage rate adjustment parameter as 0.7 .

2) Assum that the road is damaged due to disaster in the actual rescue process, and the adjustment rates of transportation resources occupancy rate TI and inventory occupancy rate adjustment parameter II are respectively 0.4 and 0.1 , and the material shortage rate adjustment parameter $\mathrm{LI}$ is 0.5 .

In the two assumptions, two recovery schemes are given. The first scheme is to recovery material $\mathrm{M}$ from place $\mathrm{A}$ for every 2 days, that is, the recovery frequency $\mathrm{R}=2$; the second scheme is to recovery material $M$ from palce $A$ for every 4 days, namely, $R=4$. The recoverable amount $\mathrm{P}$ of reusable materials is shown in Figure 5.

Recoverable amount $\mathrm{P}$

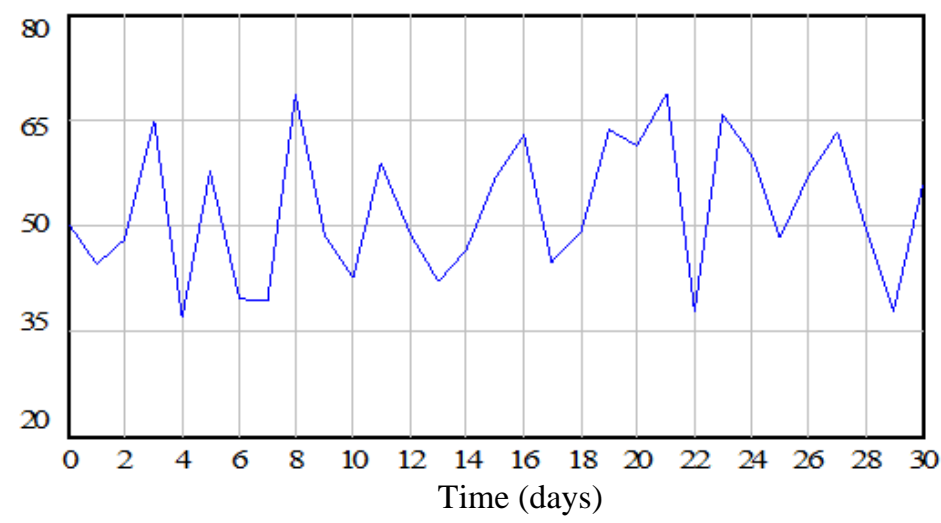

Recoverable amount $\mathrm{P}:$ Recovery frequency $\mathrm{R}=4$ Recoverable amount $\mathrm{P}:$ Recovery frequency $\mathrm{R}=2$

Figure 5. The Simulation Results Diagram of $P$

In the two schemes, the difference of the values of $\mathrm{R}$ may make the recovery amounts different and further affect the difference of demand satisfactory rate NSR which will eventually be reflected on the rescue cost curve. By running the model simulation, the results of RR, NSR and SS are as shown in Figure 6, Figure 7, and Figure 8. 


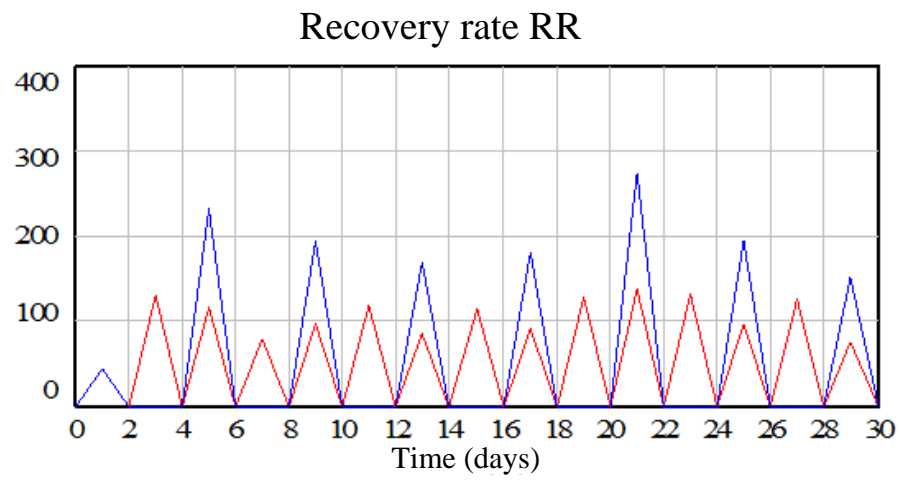

Recovery rate $\mathrm{RR}: \mathrm{TI}=0.4 \mathrm{R}=4$

Recovery rate $\mathrm{RR}$ : $\mathrm{TI}=0.4 \mathrm{R}=2$

Recovery rate $R R$ : Recovery frequency $R=2$

Recovery rate $\mathrm{RR}$ : Recovery frequency $\mathrm{R}=4$

\section{Figure 6. The Simulation Results Diagram of RR}

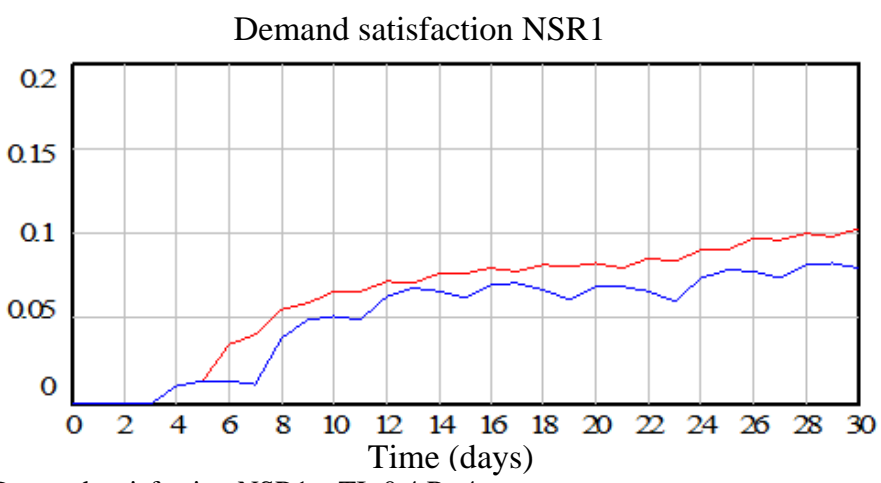

Demand satisfaction NSR1： TI $=0.4 \mathrm{R}=4$

Demand satisfaction NSR1: $\mathrm{TI}=0.4 \mathrm{R}=2$

Demand satisfaction NSR1: Recovery frequency $R=2$

Demand satisfaction NSR1: Recovery frequency $R=4$

\section{Figure 7. The Simulation Results Diagram of NSR}

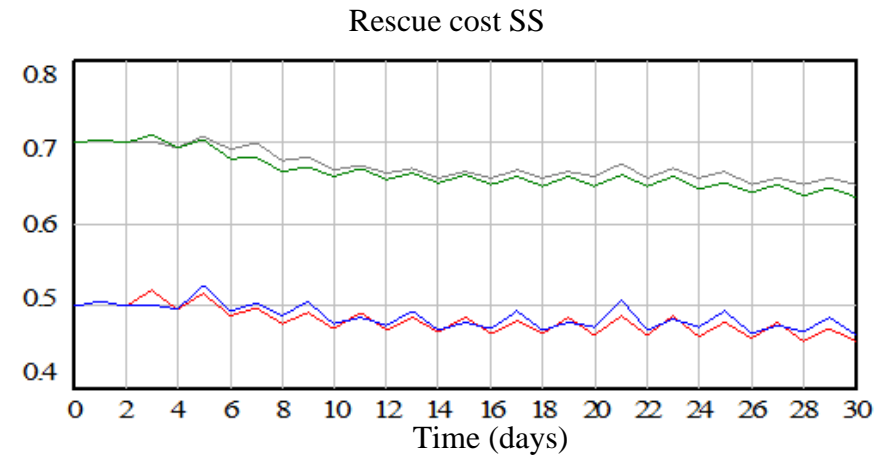

Rescue cost SS: $\mathrm{TI}=0.4 \mathrm{R}=4$

Rescue cost SS: $\mathrm{TI}=0.4 \mathrm{R}=2$

Rescue cost SS: Recovery frequency $R=2$

Rescue cost SS: Recovery frequency $\mathrm{R}=4$ 


\section{Figure 8. The Simulation Results Diagram of SS}

As shown in Figure 6, the larger $\mathrm{R}$ is, the longer the recovery interval is, and the larger the recovery amount everytime is. Figure 7, shows that NSR is only related to R. The bigger R is, the higher NSR is. But SS is not only related to recovery rate, but also the adjustment parameters of transportation, inventory and material shortage rate. As shown in Figure 8, when $\mathrm{TI}=0.2$, the higher $\mathrm{R}$ is, the lower $\mathrm{SS}$ is, and the rescue satisfaction is; when $\mathrm{TI}=0.4$, though the values of $\mathrm{R}$ are different, there are several intersections between the two curves, which shows that there is no obvious correlation between the rescue frequency and rescue satisfaction. Therefore, the rescue satisfaction is not only affected by the recovery frequency, but also affected by the transportation and inventory. The output of rescue satisfaction in the model can reflect different change rules with the changes of parameter settings.

In the practical application, preliminary judgment should be conducted based on the demands for logistics and material in actual rescue, assign the three adjustment coefficients by expert brainstorming, and assign other constants according to the actual transport time, maintenance time and maintenance rate. At last, input the recovery frequency RR, run the model for simulation. It is better to assist in the decision-making based on the result of simulation.

\section{Conclusion}

With the method of system dynamics, this paper conducts the system modeling of emergency logistics reverse recovery process in natural disasters. Comprehensively analyze the transportation resource and inventory resource of the reusable materials occupied in the recovery process at certian recovery frequency, build the system dynamics model based on recovery frequency and rescue satisfaction, simulate the system model with system dynamics softwawre Vensim, and prove the validity and practicability of the model.

\section{Acknowledgements}

This work was financially supported by project of Humanities and Social Sciences Research Project of Ministry of Education, China (14YJC630154); ZheJiang Nature Science Foundation of China (LY13G030031); ZheJiang Philosophy \& Society Science Foundation of China(16NDJC094YB); NingBo Nature Science Foundation of China (2014A610174); NingBo Soft Science Foundation of China (2014A10033); Zhejiang Federation of Humanities and Social Science Circle Foundation, China (2014Z079); The National Social Science Fund of China (14BJY233); National soft science project of China (2013GXS4D112); Social science fund project of Jilin Province (2014B321).

\section{References}

[1] Y. Liang and X. Wang, "Developing a new perspective to study the health of survivors of Sichuan earthquakes in China: a study on the effect of post-earthquake rescue policies on survivors", health-related quality of life, Health Research Policy and Systems, 11:41,1-12. DOI:10.1186/1478-4505-11-41.

[2] J. Hu and Z. Gao, "Modules identification in gene positive networks of hepatocellular carcinoma using Pearson agglomerative method and Pearson cohesion coupling modularity", Journal of Applied Mathematics, vol. 2012, (2012).

[3] Y. Geng, J. Chen, R. Fu, G. Bao and K. Pahlavan, "Enlighten Wearable Physiological Monitoring systems: On-Body RF Characteristics Based Human Motion Classification Using a Support Vector Machine", vol. 99, (2015), pp. 1-16.

[4] D. Jiang, X. Ying and Y. Han "Collaborative multi-hop routing in cognitive wireless networks", Wireless Personal Communications, (2015), pp. 1-23. 
[5] J. Hu and Z. Gao, "Modules identification in gene positive networks of hepatocellular carcinoma using Pearson agglomerative method and Pearson cohesion coupling modularity", Journal of Applied Mathematics, vol. 2012, (2012).

[6] D. Jiang, Z. Xu and Z. Chen, "Joint time-frequency sparse estimation of large-scale network traffic", Computer Networks, vol. 55, no. 15, (2011), pp. 3533-3547. J. Hu, Z. Gao and W. Pan, "Multiangle Social Network Recommendation Algorithms and Similarity Network Evaluation", Journal of Applied Mathematics, vol. 2013, (2013).

[7] M. Zhou, G. Bao, Y. Geng, B. Alkandari and X. Li, "Polyp detection and radius measurement in small intestine using video capsule endoscopy", 2014 7th International Conference on Biomedical Engineering and Informatics (BMEI), (2014) October 2.

[8] G. Yan, Y. Lv, Q. Wang and Y. Geng, "Routing algorithm based on delay rate in wireless cognitive radio network", Journal of Networks, vol. 9, no. 4, (2014) January, pp. 948-955.

[9] Y. Lin, J. Yang and Z. Lv, "A Self-Assessment Stereo Capture Model Applicable to the Internet of Things", Sensors, vol. 15, no. 8, (2015), pp. 20925-20944.

[10] K. Wang, X. Zhou and T. Li, "Optimizing load balancing and data-locality with data-aware scheduling", Big Data (Big Data), 2014 IEEE International Conference on. IEEE, (2014), pp. 119-128.

[11] L. Zhang, B. He and J. Sun, "Double Image Multi-Encryption Algorithm Based on Fractional Chaotic Time Series", Journal of Computational and Theoretical Nanoscience, vol. 12, (2015), pp. 1-7.

[12] T. Su, Z. Lv and S. Gao, "3d seabed: 3d modeling and visualization platform for the seabed", Multimedia and Expo Workshops (ICMEW), 2014 IEEE International Conference on. IEEE, (2014), pp. 1-6.

[13] Y. Geng, J. Chen, R. Fu, G. Bao and K. Pahlavan, "Enlighten wearable physiological monitoring systems: On-body rf characteristics based human motion classification using a support vector machine", IEEE transactions on mobile computing, vol. 1, no. 1, (2015) April, pp. 1-15

\section{Authors}

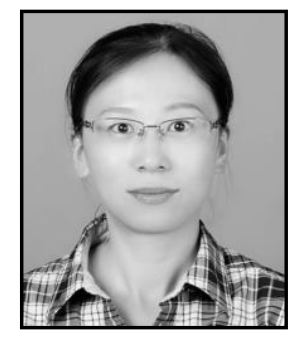

Ying $\mathbf{X u}$, She got her $\mathrm{PhD}$ degree of Management science and Engineering from School of Management, University of Shanghai for Science and Technology, China. She is associate professor at Ningbo Dahongying University, Ningbo, China. She is also hired as an associate professor of science and research at Sias International University of Zhengzhou University, Zhengzhou, China. Her main research interests are including supply chain optimization and electronic commerce. She has dozens of papers published in national and international journals, and has contributed to, edited and published several books related to relevant research field. 
International Journal of $u-$ and e- Service, Science and Technology Vol. 9, No. 12 (2016) 